$$
\begin{aligned}
& \text { Paul Eugene Lovis Z Zurerier } \\
& \text { * UNE }
\end{aligned}
$$

\title{
FORME PARTICULIÈRE
}

\section{DES \\ FAUSSES DÉGRÉTALES}

D'APRÈS

UN MANUSGRIT DE LA GRANDE-CHARTREUSE.

Le manuscrit $n^{\circ} 473$ de la bibliothèque de la ville de Grenoble a été exécuté à la Grande-Chartreuse dans la seconde moitié du xII $^{\mathbf{e}}$ siècle ${ }^{1}$. Il a été conservé à la Chartreuse jusqu'au commencement $d u x x^{e}$ siècle, époque à laquelle les manuscrits chartreux furent transportés à la bibliothèque de la ville de Grenoble.

Ce manuscrit contient les Fausses Décrétales, suivies du Liber Pontificalis $^{2}$ et de la lettre adressée à Alexandre II par le clergé et le peuple de Florence pour lui apprendre le miracle de Pierre Igné $^{3}$. M. Hinschius ne l'a point connu et par suite n'a pu l'utiliser pour la préparation de son édition des Fausses Décrétales; le manuscrit de Grenoble a d'abord été signalé par M. de Schulte, qui, dans son Iter Gallicum 4 , en a donné une description assez complète. Cependant, M. de Schulte n'a pas identifié les éléments les plus importants de cette collection.

1. Écrit sur parchemin, 269 feuillets; 497 sur 352 millim. Reliure du xvin' siècle en basane à filets. Je désigne ce manuscrit par le numéro du nouvel inventaire, qui formera le tome VII de la collection in- $8^{\circ}$, en cours de publication, des Catalogues des manuscrits des bibliothèques des départements. A la Grande-Chartreuse, il portait le $n^{\circ} 121$, et plus tard, à la bibliothèque de Grenoble, il portait le $n \cdot 16$.

2. Ce manuscrit a èté étudié par M. l'abbé Duchesne pour son édition du Liber Pontificalis; cf. t. I, p. cxc.

3. Cf. Migne, Patrologie Latine, Acta S. Johannis Gualberti, CXIVI, 797 et ss.

4. Tome LXIV des Sitzungsberichte der philos.-histor. Cl. der kais. Akademie der Wissenchaften, pp. 369 et ss. 